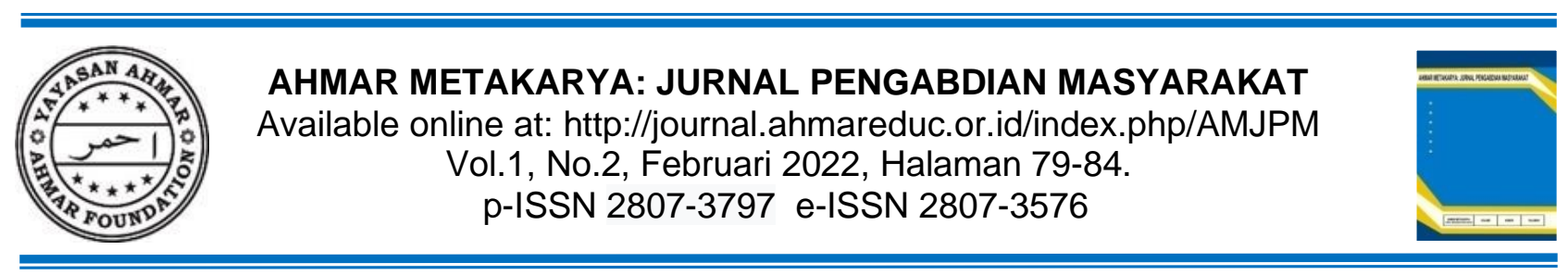

\title{
Membangun Generasi Berkualitas dengan Keluarga yang Terencana serta Pemeriksaan Kesehatan Gratis
}

\author{
Putri Kurniawati \\ Akademi Kebidanan Saleha, Banda Aceh, Indonesia \\ *E-mail: putriniazi87@gmail.com
}

Received: 29 Januari 2022

Accepted: 25 Februari 2022

Published: 28 Februari 2022

\begin{abstract}
Family planning is an attempt to measure the number of children and the desired birth spacing of children. Therefore, the Government has launched a program or method to prevent and delay pregnancy. The purpose of the family planning program is to form a small family in accordance with the socio-economic strength of a family by regulating the birth of children in order to obtain a happy and prosperous family that can fulfill their needs and carry out their daily activities. free examination and counseling for the recovery of a disease in the community in Beurandeh Village. The method used the first step: a series of coordination, survey and licensing activities, and procurement of facilities and infrastructure (initial logic). Meeting with the head of Beurandeh village, Masjid Raya sub-district, Aceh Besar district. Second step: setting up a command post, disseminating information, collecting data. Third step: improvement steps when in the field in the form of free inspections and providing information on how to build a quality generation with a planned family. The results obtained in the community service program in Beurandeh Village can be carried out properly and smoothly according to the activity plans that have been prepared, although not all Beurandeh people have the awareness to live a healthy life. This activity received a very good response from the community as evidenced by the activeness and presence of the community to take part in free health check-ups by not leaving the activity/place before the time ended. The conclusion is in conducting free checks on the people of Beurandeh Village and providing knowledge about how to build a quality generation with a planned family., knowing about hypertension, blood sugar, gout, by providing knowledge about health, Beurandeh village people can be more careful in eating food that is too excessive, people can also adjust their diet and exercise to reduce the disease they experience or prevent the disease. Because prevention is better than cure. Suggestion Given that many people are less concerned about health, therefore it is necessary to conduct free health checks to reduce the mortality rate caused by chronic diseases.
\end{abstract}

Keywords: Family Planning, Free Health Check.

\begin{abstract}
Abstrak
Keluarga berencana merupakan usaha untuk mengukur jumlah anak dan jarak kelahiran anak yang diinginkan. Maka dari itu, Pemerintah mencanangkan program atau cara untuk mencegah dan menunda kehamilan .Tujuan dilaksanakan program KB yaitu untuk membentuk keluarga kecil sesuai dengan kekuatan sosial ekonomi suatu keluarga dengan cara pengaturan kelahiran anak agar diperoleh suatu keluarga bahagia dan sejahtera yang dapat memenuhi kebutuhan hidupnya dan melakukan pemeriksaan gratis serta konseling untuk pemulihan suatu penyakit pada masyarakat di Desa Beurandeh.Metode yang digunakan Langkah pertama : serangkaian koordinasi, kegiatan survey dan perijinan, serta pengadaan sarana dan prasarana (logisik awal). Pertemuan dengan kepala desa Beurandeh kecamatan Masjid Raya Kabupaten aceh Besar.Langkah kedua : pembuatan posko, penyebaran informasi, pengumpulan data.Langkah ketiga : langkah-langkah penyempurnaan ketika di lapangan berupa pemeriksaan gratis dan memberikan informasi tentang cara membangun generasi berkualitas dengan keluarga yang terencana. Hasil yang didapatkan dalam Program pengabdian kepada masyarakat di Desa Beurandeh dapat diselenggarakan dengan baik
\end{abstract}


dan lancar sesuai dengan rencana kegiatan yang telah disusun, meskipun belum semua masyarakat Beurandeh memiliki kesadaran untuk hidup sehat. Kegiatan ini mendapatkan sambutan yang sangat baik dari masyarakat terbukti dengan keaktifan dan kehadiran masyarakat untuk mengikuti kegiatan pemeriksaan kesehatan gratis dengan tidak meninggalkan kegiatan/tempat sebelum waktu berakhir. Kesimpulan dalam melakukan pemeriksaan gratis pada masyarakat Desa Beurandeh dan memberikan pengetahuan tentang cara membangun generasi berkualitas dengan keluarga yang terencana., mengetahui tentang hipertensi, gula darah, asam urat, dengan memberi pengetahuan tentang kesehatan, masyarakat desa Beurandeh bisa lebih berhati-hati dalam memakan makanan yang terlalu berlebihan, masyarakat juga bisa mengatur pola makan, dan berolahraga untuk mengurangi penyakit yang dialami atau mencegah penyakit tersebut. Karena mencegah lebih baik dari pada mengobati. Saran Mengingat banyaknya masyarakat yang kurang peduli akan kesehatan, maka dari itu perlu dilakukan pemeriksaan kesehatan gratis untuk mengurangi Angka Kematian yang disebabkan oleh penyakit-penyakit kronik.

Kata Kunci: Keluarga Berencana, Pemeriksaan Kesehatan Gratis.

\section{A. PENDAHULUAN}

Hasil Sensus Penduduk 2010 menempatkan posisi Indonesia di urutan keempat dalam jumlah penduduk setelah China, India, dan USA. Kecenderungan jumlah penduduk di Indonesia semakin meningkat tiap tahunnya. Hal ini diperkuat data Badan Pusat Statistik (BPS) bahwa jumlah penduduk Indonesia pada tahun 2010 sejumlah 194.754 .808 jiwa, tahun 2011 adalah 206.264.595 jiwa dan tahun 2012 mencapai 237.641.326 jiwa (Badan Pusat Statistik, 2014).

Keluarga berencana merupakan usaha untuk mengukur jumlah anak dan jarak kelahiran anak yang diinginkan. Maka dari itu, Pemerintah mencanangkan program atau cara untuk mencegah dan menunda kehamilan. Kesehatan merupakan hak asasi manusia dan investasi untuk keberhasilan pembangunan bangsa. Untuk itu perlu diselenggarakan pengembangan kesehtan secara menyuluruh agar terwujud masyarakat yang sehat (Sulistyoningsih, 2020).

Sasaran program KB adalah Pasangan Usia Subur (PUS) yang lebih dititikberatkan pada kelompok Wanita Usia Subur (WUS) yang berada pada kisaran usia 15-49 tahun. Tingkat kesertaan untuk mengikuti KB diukur dari angka PUS yang menjadi peserta keluarga berencana (KB). Persentase peserta KB baru terhadap pasangan usia subur di Indonesia pada tahun 2015 sebesar 13,46\%. Angka ini lebih rendah dibandingkan capaian tahun 2014 yang sebesar 16,51\%. Data Riset Kesehatan Nasional 2018 menunjukan bahwa wanita usia subur yang bersia 15-49 tahun dengan status kawin sebagian besar $59,3 \%$ menggunakan metode kontrasepsi modern seperti suntikan, pil, implant, Intra Uterine Device(IUD), sedangkan sekitar $0,4 \%$ wanita menggunakan metode KB tradisional seperti metode kalender, Metode Amenore Laktasi (MAL), senggama terputus (coitus interuptus) dan lainnya, sekitar 24,7\% pernah menggunakan Metode kontrasepsi tetapi karena alasan tertentu maka tidak menggunakan lagi serta terdapat 15,5\% tidak pernah menggunakan alat kontrasepsi (Kemenkes RI, 2018).

Masyarakat sejahtera adalah suatu kondisi terpenuhinya kesejahteraan lahir dan batin, serta sehat jasmani dan rohani. Kondisi sehat jasmani dan rohani pada setiap individu adalah suatu keadaan sementara, karena dalam kehidupan manusia terdapat sifat hakiki yaitu suatu sifat "tidak kekal". Sifat tidak kekal ini, selalu meliputi dan mengikuti manusia, baik sebagai pribadi maupun dalam kelompok atau dalam bagian kelompok masyarakat dalam melaksanakan akivitas hidupnya (Hartono, 2008).

Kurangnya kesadaran masyarakat untuk melakukan pemeriksaan kesehatan rutin untuk mencegah penyakit masih kurang. (Hardani, 2018). Masyarakat dewasa ini cendrung lebih mengonsumsi makanan yang kurang sehat. jeroan dan kacang-kacangan dikategorikan sebagai makanan dengan kandungan purin yang relative tinggi sehingga berpotensi meningkatkan kadar asam urat, terlebih jika tidak diikuti oleh pola hidup yang sehat (Hamdani et al, 2011 ; Aminah, 2012 ; Damayanti, 2013 ; Angelina et al, 2014).

Tujuan dilaksanakan program KB yaitu untuk membentuk keluarga kecil sesuai dengan kekuatan sosial ekonomi suatu keluarga dengan cara pengaturan kelahiran anak agar diperoleh suatu keluarga bahagia dan sejahtera yang dapat memenuhi kebutuhan hidupnya (Sulistyoningsih, 
2020). Serta dibuatnya pemeriksaan kesehatan gratis mengingat banyaknya masyarakat yang kurang peduli akan kesehatan, maka dari itu perlu dilakukan pemeriksaan kesehatan gratis untuk mengurangi Angka Kematian yang disebabkan oleh penyakit-penyakit kronik. Melalui pengabdian masyarakat diharapkan para mahasiswa dapat menerapkan ilmu pengetahuan yang dimiliki dan para masyakat dapat mengetahui kondisi tubuhnya serta menerima manfaat yang diberikan.

\section{B. METODE DAN PELAKSANAAN}

Metode yang digunakan dalam pengabdian masyarakat ini yaitu ada beberapa langkah yang dilakukan yaitu:

1. Serangkaian koordinasi, kegiatan survey dan perijinan, serta pengadaan sarana dan prasarana (logisik awal). Pertemuan dengan kepala desa Beurandeh kecamatan Masjid Raya Kabupaten aceh Besar.

2. Pembuatan posko, penyebaran informasi, pengumpulan data.

3. Langkah-langkah penyempurnaan ketika di lapangan berupa pemeriksaan gratis dan memberikan informasi tentang cara membangun generasi berkualitas dengan keluarga yang terencana.

Dalam proses kegiatan kemanusiaan tersebut, Posko Pelayanan Kesehatan Akbid Saleha di dirikan di Desa Beurandeh, pada tanggal 09 Maret 2021. Jenis kegiatan yang dilakukan yaitu Pengabdian Masyarakat serta Pemeriksaan Kesehatan Gratis.

\section{HASIL DAN PEMBAHASAN}

Keluarga berencana merupakan usaha untuk mengukur jumlah anak dan jarak kelahiran anak yang diinginkan. Maka dari itu, Pemerintah mencanangkan program atau cara untuk mencegah dan menunda kehamilan (Sulistyoningsih, 2020). Tujuan program KB lainnya yaitu untuk menurunkan angka kelahiran yang bermakna, untuk mencapai tujuan tersebut maka diadakan kebijakaan yang dikategorikan dalam tiga fase (menjarangkan, menunda, dan menghentikan) maksud dari kebijakaan tersebut yaitu untuk menyelamatkan ibu dan anak akibat melahirkan pada usia muda, jarak kelahiran yang terlalu dekat dan melahirkan pada usia tua (Hartanto, 2004).

Program pengabdian masyarakat kepada masyarakat di Desa Beurandeh dapat diselenggarakan dengan baik dan lancar sesuai dengan rencana kegiatan yang telah disusun, meskipun belum semua masyarakat Beurandeh memiliki kesadaran untuk hidup sehat. Kegiatan ini mendapatkan sambutan yangsangat baik dari masyarakat Beurandeh terbukti dengan keaktifan dan kehadiran masyarakat Beurandeh untuk mengikuti kegiatan pemeriksaan gratis kesehatan Akademi Kebidanan Saleha Banda Aceh dengan tidak meninggalkan kegiatan sebelum waktu berakhir.

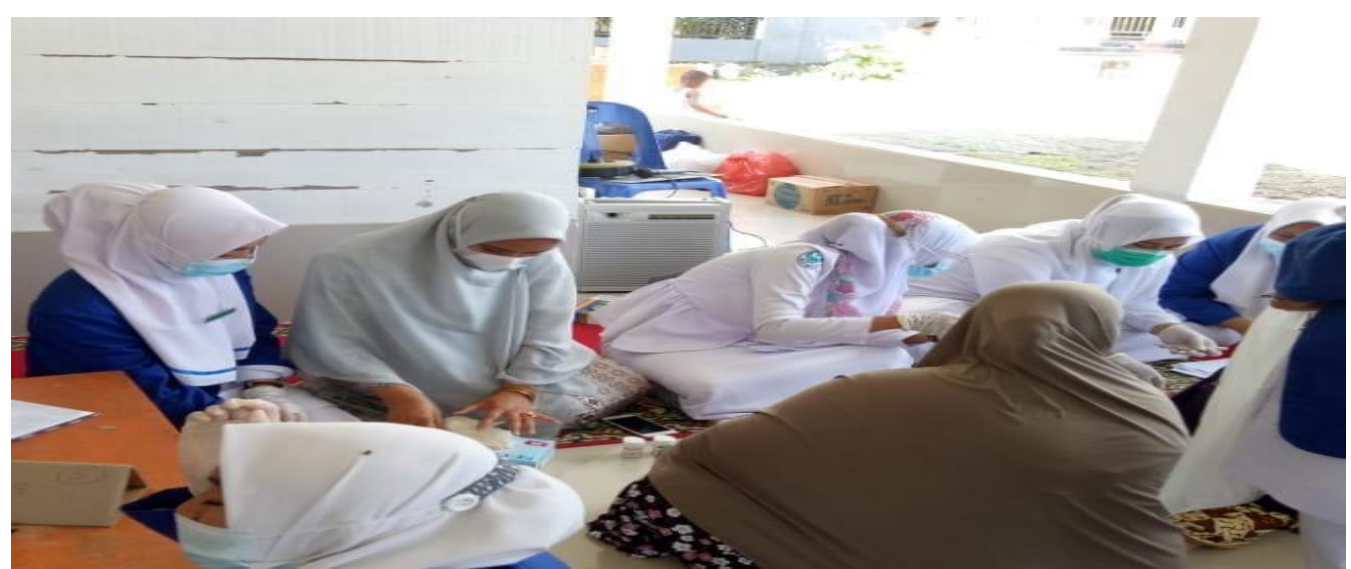

Gambar 1. Antrian pendaftaran pemeriksaan dan pengobatan gratis 


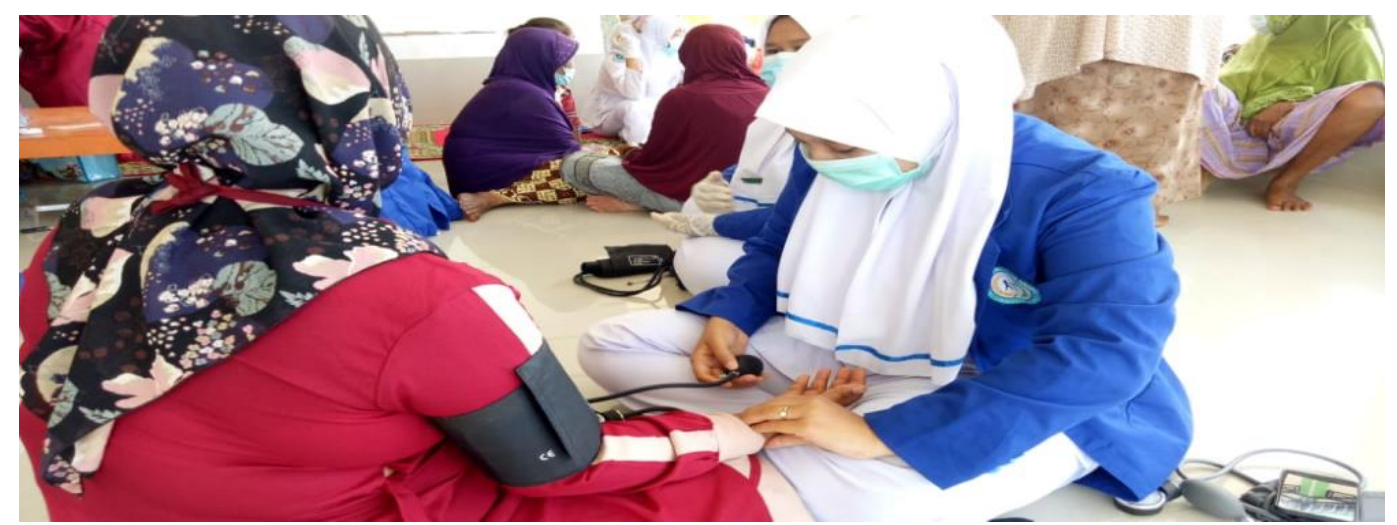

Gambar 2. Pemeriksaan Tekanan Darah

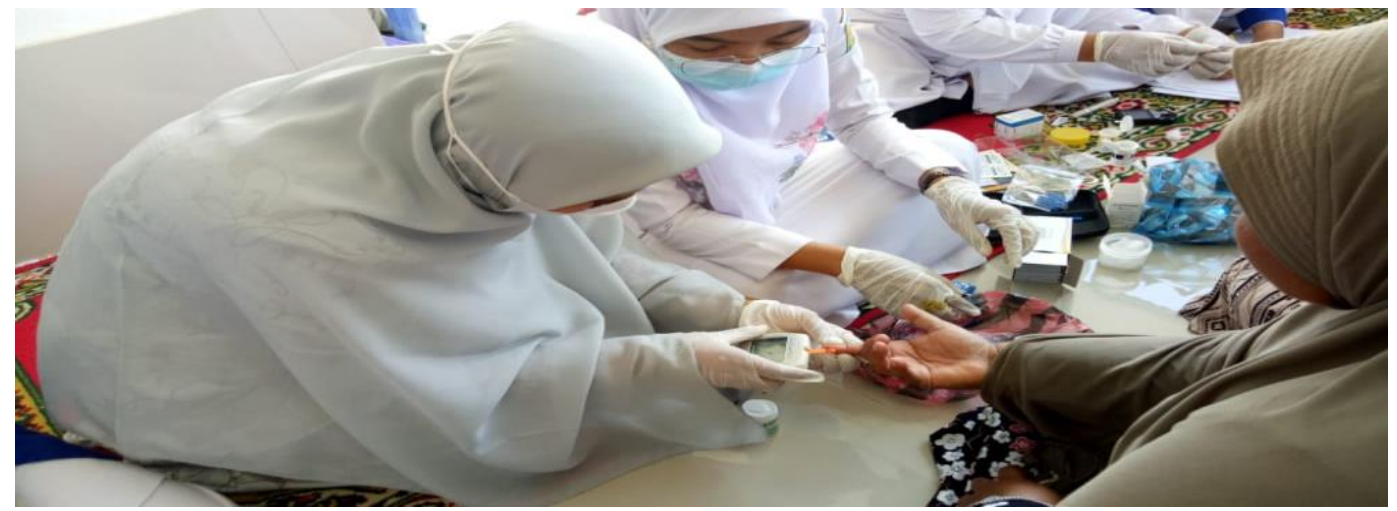

Gambar 3. Pemeriksaan Gula Darah

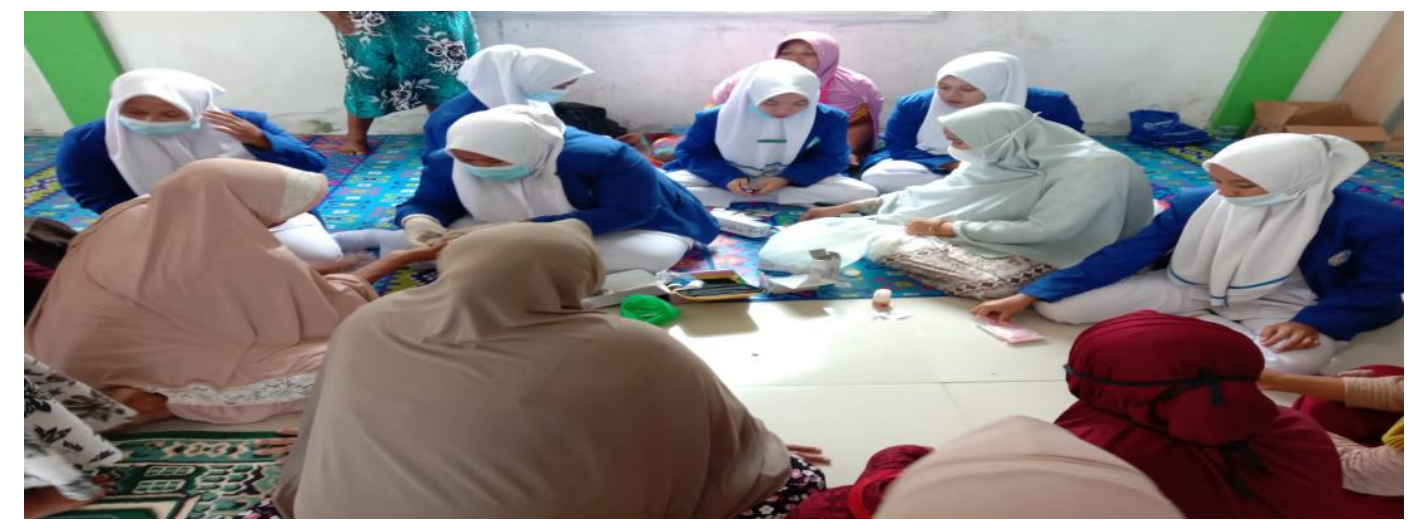

Gambar 4. Pemeriksaan kolesterol dan pemberian obat gratis

Tabel 1. Hasil kegiatan pemeriksaan kesehatan gratis.

\begin{tabular}{|c|c|c|c|c|c|c|}
\hline No & Nama & Umur & Alamat & $\begin{array}{c}\text { Jenis } \\
\text { Pemeriksaan }\end{array}$ & Hasil & Diagnosa \\
\hline 1 & Zainal & 60 & Beurandeh & $\begin{array}{c}\text { Tekanan Darah, } \\
\text { Glukosa }\end{array}$ & $\begin{array}{c}140 / 90 \mathrm{mmHg}, \\
125 \mathrm{mg} / \mathrm{dl}\end{array}$ & Hipertensi \\
\hline 2 & Jawiliah & 45 & Beurandeh & Asam urat & $7,5 \mathrm{mg} / \mathrm{dL}$ & Normal \\
\hline 3 & Fatimah & 35 & Beurandeh & $\begin{array}{c}\text { Glukosa, tekanan } \\
\text { darah }\end{array}$ & $\begin{array}{c}127 \mathrm{mg} / \mathrm{dL}, \\
120 / 80 \mathrm{mmHg}\end{array}$ & Normal \\
\hline 4 & Kartini & 38 & Beurandeh & $\begin{array}{c}\text { Tekanan Darah, } \\
\text { glukosa }\end{array}$ & $\begin{array}{c}140 / 90 \mathrm{mmHg}, \\
120 \mathrm{mg} / \mathrm{dl}\end{array}$ & Hipertensi \\
\hline 5 & Lia & 40 & Beurandeh & $\begin{array}{c}\text { Tekanan Darah, } \\
\text { asam urat }\end{array}$ & $\begin{array}{c}120 / 70 \mathrm{mmHg} \\
4,6 \mathrm{mg} / \mathrm{dL}\end{array}$ & Normal \\
\hline 6 & Fariant & 40 & Beurandeh & $\begin{array}{c}\text { Tekanan darah, } \\
120 / 70 \mathrm{mmHg},\end{array}$ & Normal \\
\hline
\end{tabular}


Kurniawati, P. (2022). Membangun Generasi Berkualitas dengan Keluarga yang Terencana serta Pemeriksaan Kesehatan Gratis. Ahmar Metakarya: Jurnal Pengabdian Masyarakat, 1 (2), 79-84.

\begin{tabular}{|c|c|c|c|c|c|c|}
\hline & & & & asam urat & $4,5 \mathrm{mg} / \mathrm{dl}$ & \\
\hline 7 & Wina sara & 35 & Beurandeh & $\begin{array}{l}\text { Tekanan darah, } \\
\text { asam urat }\end{array}$ & $\begin{array}{c}110 / 80 \mathrm{mmHg} \\
4,5 \mathrm{mg} / \mathrm{dL}\end{array}$ & Normal \\
\hline 8 & Laila & 26 & Beurandeh & $\begin{array}{c}\text { Tekanan Darah, } \\
\text { glukosa }\end{array}$ & $\begin{array}{c}130 / 80 \mathrm{mmHg}, \\
125 \mathrm{mg} / \mathrm{dl}\end{array}$ & Normal \\
\hline 9 & Fitri & 31 & Beurandeh & $\begin{array}{l}\text { Tekanan darah, } \\
\text { Glukosa }\end{array}$ & $\begin{array}{c}120 / 70 \mathrm{mmHg} \\
142 \mathrm{mg} / \mathrm{dL}\end{array}$ & Normal \\
\hline 10 & Nurmiati & 25 & Beurandeh & $\begin{array}{l}\text { Tekanan darah, } \\
\text { asam urat }\end{array}$ & $\begin{array}{c}140 / 80 \mathrm{mmH} \\
7,5 \mathrm{mg} / \mathrm{dl}\end{array}$ & Hipertensi \\
\hline 11 & Sarifa & 21 & Beurandeh & $\begin{array}{c}\text { Glukosa, tekanan } \\
\text { darah }\end{array}$ & $\begin{array}{c}100 / 70 \mathrm{mmHg} \\
120 \mathrm{mg} / \mathrm{dL}\end{array}$ & Normal \\
\hline 12 & Ramlah & 33 & Beurandeh & $\begin{array}{l}\text { Tekana darah } \\
\text { Glukosa }\end{array}$ & $\begin{array}{c}130 / 70 \mathrm{mmHg} \\
233 \mathrm{mg} / \mathrm{dL}\end{array}$ & DM \\
\hline 13 & Rukiyah & 37 & Beurandeh & $\begin{array}{l}\text { Tekanan darah, } \\
\text { asam urat }\end{array}$ & $\begin{array}{c}130 / 90 \mathrm{mmHg} \\
6,5 \mathrm{mg} / \mathrm{dl}\end{array}$ & Normal \\
\hline 14 & Sabidah & 62 & Beurandeh & $\begin{array}{l}\text { Tekanan darah, } \\
\text { asam urat }\end{array}$ & $\begin{array}{c}160 / 90 \mathrm{mmHg} \\
6.5 \mathrm{mg} / \mathrm{dL}\end{array}$ & Hipertensi \\
\hline 15 & Rahayu & 54 & Beurandeh & $\begin{array}{l}\text { Tekanan darah, } \\
\text { asam urat }\end{array}$ & $\begin{array}{c}150 / 90 \mathrm{mmHg} \\
6,5 \mathrm{mg} / \mathrm{dL}\end{array}$ & Hipertensi \\
\hline 16 & Halimah & 46 & Beurandeh & $\begin{array}{l}\text { Tekanan darah } \\
\text { Glukosa }\end{array}$ & $\begin{array}{c}140 / 80 \mathrm{mmHg} \\
210 \mathrm{mg} / \mathrm{dL}\end{array}$ & DM \\
\hline 17 & Julaika & 43 & Beurandeh & $\begin{array}{l}\text { Tekanan darah, } \\
\text { alargi }\end{array}$ & $110 / 70 \mathrm{mmHg}$ & Normal \\
\hline 18 & Nurmala & 36 & Beurandeh & $\begin{array}{c}\text { Tekanan darah, } \\
\text { glukosa }\end{array}$ & $\begin{array}{c}120 / 80 \mathrm{mmHg}, \\
130 \mathrm{mg} / \mathrm{dl}\end{array}$ & Normal \\
\hline 19 & Mailani & 46 & Beurandeh & $\begin{array}{l}\text { Tekanan darah, } \\
\text { asam urat }\end{array}$ & $\begin{array}{c}140 / 90 \mathrm{mmHg}, \\
6,5 \mathrm{mg} / \mathrm{dl}\end{array}$ & Hipertensi \\
\hline 20 & Juwiyah & 36 & Beurandeh & $\begin{array}{l}\text { Tekanan darah } \\
\text { Glukosa }\end{array}$ & $\begin{array}{c}120 / 70 \mathrm{mmHg} \\
140 \mathrm{mg} / \mathrm{dL}\end{array}$ & Normal \\
\hline 21 & Karmila & 40 & Beurandeh & $\begin{array}{l}\text { Tekanan darah, } \\
\text { asam urat }\end{array}$ & $\begin{array}{c}130 / 80 \mathrm{mmHg} \\
6,5 \mathrm{mg} / \mathrm{dL}\end{array}$ & DM \\
\hline 22 & Maysarah & 36 & Beurandeh & $\begin{array}{c}\text { Tekana darah } \\
\text { Glukosa }\end{array}$ & $\begin{array}{c}130 / 80 \mathrm{mmHg} \\
255 \mathrm{mg} / \mathrm{dL}\end{array}$ & DM \\
\hline 23 & Khatijah & 41 & Beurandeh & $\begin{array}{l}\text { Tekanan darah, } \\
\text { asam urat }\end{array}$ & $\begin{array}{c}130 / 80 \mathrm{mmHg} \\
8,5 \mathrm{mg} / \mathrm{dl}\end{array}$ & Asam urat \\
\hline 24 & Siti & 26 & Beurandeh & $\begin{array}{l}\text { Tekanan darah } \\
\text { Glukosa }\end{array}$ & $\begin{array}{c}120 / 80 \mathrm{mmHg}, \\
130 \mathrm{mg} / \mathrm{dl}\end{array}$ & Normal \\
\hline 25 & Khairan & 31 & Beurandeh & $\begin{array}{l}\text { Tekanan darah, } \\
\text { asam urat }\end{array}$ & $\begin{array}{c}130 / 80 \mathrm{mmHg} \\
6,5 \mathrm{mg} / \mathrm{dl}\end{array}$ & Normal \\
\hline 26 & Santi & 36 & Beurandeh & $\begin{array}{l}\text { Tekanan darah, } \\
\text { asam urat }\end{array}$ & $\begin{array}{c}150 / 90 \mathrm{mmHg}, \\
6,5 \mathrm{mg} / \mathrm{dl}\end{array}$ & Hipertensi \\
\hline 27 & M. ilham & 49 & Beurandeh & $\begin{array}{c}\text { Tekanan darah, } \\
\text { alergi }\end{array}$ & $130 / 80 \mathrm{mmHg}$ & Normal \\
\hline 28 & Edi putra & 25 & Beurandeh & $\begin{array}{c}\text { Tekanan darah, } \\
\text { sakit gigi }\end{array}$ & $120 / 80 \mathrm{mmHg}$ & Normal \\
\hline 29 & Usman & 20 & Beurandeh & Tekanan darah & $120 / 80 \mathrm{mmHg}$ & Normal \\
\hline 30 & $\begin{array}{l}\text { M. rispan } \\
\text { raju }\end{array}$ & 25 & Beurandeh & $\begin{array}{l}\text { Tekanan darah } \\
\text { Glukosa }\end{array}$ & $\begin{array}{c}120 / 80 \mathrm{mmHg}, \\
130 \mathrm{mg} / \mathrm{dl}\end{array}$ & Normal \\
\hline 31 & $\begin{array}{c}\text { Andisa } \\
\text { nofal }\end{array}$ & 26 & Beurandeh & $\begin{array}{c}\text { Tekanan darah } \\
\text { Glukosa }\end{array}$ & $\begin{array}{c}120 / 80 \mathrm{mmHg}, \\
120 \mathrm{mg} / \mathrm{dl}\end{array}$ & Normal \\
\hline 32 & Firdaus & 22 & Beurandeh & Tekanan darah & $120 / 80 \mathrm{mmHg}$ & Normal \\
\hline 33 & Zulfikar & 25 & Beurandeh & Tekanan darah, & $110 / 80 \mathrm{mmHg}$ & Normal \\
\hline
\end{tabular}




\begin{tabular}{|c|c|c|l|c|c|c|}
\hline & & & & asam urat & $6,5 \mathrm{mg} / \mathrm{dl}$ & Normal \\
\hline 34 & M. tengku & 50 & Beurandeh & $\begin{array}{c}\text { Tekanan darah, } \\
\text { sakit gigi }\end{array}$ & $100 / 80 \mathrm{mmHg}$ & Normal \\
\hline 35 & Jailani Z & 46 & Beurandeh & $\begin{array}{c}\text { Tekanan darah, } \\
\text { alergi }\end{array}$ & $110 / 80 \mathrm{mmHg}$ & Normal \\
\hline 36 & Zainal & 27 & Beurandeh & Tekanan darah & $110 / 80 \mathrm{mmHg}$ & Nanal \\
\hline
\end{tabular}

Setelah dilakukan pemerikasaan kesehatan gratis pada masyarakat beurandeh kecamatan mesjid raya kabupaten aceh besar, disini ada beberapa pemeriksaan yang dicek yaitu: Hipertensi, Diabetes Militus, Asam Urat maka ditemukan beberapa hasil yaitu: yang masyarakat hipertensi sebanyan 7 orang, DM 4 orang asam urat sebanyak 1 orang dan yang normal sebanyak 24 orang, dari hasil tersebut masyarakat menyadari bahwa pentingnya mengkonsumsi makanan yang sehat, dan pentingnya melakukan pemeriksaan diri pada tenaga kesehatan dan selalu berhati-hati dalam mengolah dan mengkonsumsi makanan yang terlalu berlebihan, masyarakat juga bisa mengatur pola makan, dan berolahraga untuk mengurangi penyakit yang dialami atau mencegah penyakit tersebut. Karena mencegah lebih baik dari pada mengobati.

\section{KESIMPULAN}

Dalam melakukan pemeriksaan gratis pada masyarakat Desa Beurandeh dan memberikan pengetahuan tentang cara membangun generasi berkualitas dengan keluarga yang terencana., mengetahui tentang hipertensi, gula darah, asam urat, dengan memberi pengetahuan tentang kesehatan, masyarakat desa Beurandeh bisa lebih berhati-hati dalam memakan makanan yang terlalu berlebihan, masyarakat juga bisa mengatur pola makan, dan berolahraga untuk mengurangi penyakit yang dialami atau mencegah penyakit tersebut. Karena mencegah lebih baik dari pada mengobati. Program pengabdian masyarakat kepada masyarakat di Desa Beurandeh dapat diselenggarakan dengan baik dan lancar sesuai dengan rencana kegiatan yang telah disusun, meskipun belum semua masyarakat Beurandeh memiliki kesadaran untuk hidup sehat. Kegiatan ini mendapatkan sambutan yangsangat baik dari masyarakat Beurandeh terbukti dengan keaktifan dan kehadiran masyarakat Beurandeh untuk mengikuti kegiatan pemeriksaan gratis kesehatan Akademi Kebidanan Saleha Banda Aceh dengan tidak meninggalkan kegiatan sebelum waktu berakhir.

\section{DAFTAR PUSTAKA}

Angelina, F., Kusmiyati, D. K., \& Wirawanni, Y. (2014). Perbedaan pengaruh asupan kacang tanah (Arachis hypogaea) rebus dan panggang terhadap kadar asam urat dalam darah pada wanita dislipidemia. Journal of nutrition college, 3(2), 278-284.

Aminah, M. S. (2012). Ajaibnya Tumpas Penyakit Asam Urat. Jakarta: Dunia Sehat.

Badan Pusat Statistik. (2014). Survei Demografi dan Kesehatan Indonesia. Jakarta: Badan Pusat Statistik.

Damayanti, D. (2013). Sembuh Total Diabetes Asam Urat Hipertensi Tanpa Obat.

Hartono, S. R. (2008). Hukum Asuransi dan Perusahaan Asuransi. Jakarta: Sinar Grafika.

Hamdani, S. P. G, Haman, H., Susetyowati. (2011). High consumption of carbohydrate, Protein, Fat as risk factor of Dislipidemia in Lectures of Gadjah Mada University (GMU) having medical check up at GMC Health Centre Yogyakarta. Program Faculty of Medicine Gadjah Mada University Yogyakarta

Hardani, H., Mustariani, B. A. A., Suhada, A., \& Aini, A. (2018). Pemeriksaan Golongan Darah Sebagai Upaya Peningkatan Pemahaman Siswa Tentang Kebutuhan Dan Kebermanfaatan Darah. JMM (Jurnal Masyarakat Mandiri), 2(1), 8-12.

Kemenkes, R. I. (2018) Riset Kesehatan Dasar. Jakarta: Kementerian Kesehatan Republik Indonesia.

Sulistyoningsih, H., \& Hawa, A. B. (2020). Gambaran partisipasi pasangan usia subur dalam program keluarga berencana di Desa Cikadongdong Kecamatan Singaparna tahun 2018. Jurnal Kesehatan Bidkesmas Respati, 2(11), 45-52. 